\title{
Avoiding harm from overprescribing: what are the challenges and how do we overcome them?
}

\author{
Lauren (GUEST EDITOR) Walker ${ }^{1}$ and Arduino Mangoni ${ }^{2}$ \\ ${ }^{1}$ University of Liverpool School of Life Sciences \\ ${ }^{2}$ Flinders University and Flinders Medical Centre
}

December 4, 2020

\begin{abstract}
This themed issue follows a meeting held at the Royal College of Physicians in London in November 2019 entitled "Avoiding harm from overprescribing: how to reduce waste and dependence on prescription drugs." Here we summarize the existing challenges faced by healthcare professionals and attempt to present solutions to the expanding problem associated with a vast therapeutic arsenal and increasing medical complexity.
\end{abstract}

\section{Hosted file}

overprescribing editorial v2.pdf available at https://authorea.com/users/381294/articles/ 497125-avoiding-harm-from-overprescribing-what-are-the-challenges-and-how-do-weovercome-them 